\title{
Detection of heat and cold waves in Montevergine time series (1884-2015)
}

\author{
Vincenzo Capozzi and Giorgio Budillon \\ Department of Science and Technology, University of Naples "Parthenope", Centro Direzionale di Napoli, \\ 80143, Napoli, Italy
}

Correspondence to: Vincenzo Capozzi (vincenzo.capozzi@uniparthenope.it)

Received: 29 November 2016 - Revised: 2 March 2017 - Accepted: 7 April 2017 - Published: 12 May 2017

\begin{abstract}
In recent years, extreme events related to cooling and heating have taken high resonance, motivating the scientific community to carry out an intensive research activity, aimed to detect their variability and frequency. In this work, we have investigated about the frequency, the duration, the severity and the intensity of heat and cold waves in a Southern Italy high-altitude region, by analysing the climatological time series collected in Montevergine observatory. Following the guidelines provided by CLIVAR project (Climate and Ocean Variability, Predictability and Change), we have adopted indicators based on percentiles and duration to define a heat wave and cold event.

Main results have highlighted a strong and significant positive trend in the last 40 years (1974-2015) in heat waves frequency, severity and intensity. On the contrary, in recent decades, cold wave events have exhibited a significant and positive trend only in intensity. Moreover, through the usage of two Wavelet Analysis tools, the Cross Wavelet Transform and the Wavelet Coherence, we have investigated about the connections between the extreme temperature events occurred in Montevergine and the large-scale atmospheric patterns. The heat wave events have exhibited relevant relationships with the Western European Zonal Circulation and the North Atlantic Oscillation, whereas the variability of cold wave events have shown linkages with the Eastern Mediterranean Pattern and the North Sea Caspian Pattern. In addition, the main features of synoptic patterns that have caused summer heat waves and winter cold waves in Montevergine site are presented.
\end{abstract}

\section{Introduction}

According to the last reports (e.g. IPCC, 2014) provided by the Intergovernmental Panel on Climate Change (IPCC), the last thirty years have been characterized not only by a significant temperature rise (e.g. Hansen et al., 2006), but also by an increasing frequency of extreme events (e.g. Alexander et al., 2006), as a result of climate change.

Europe has experienced a lot of extreme events over the last decade, including temperature extremes, named heat and cold waves. As an example, the heat wave occurred in 2003 in the western Europe (e.g. Beniston, 2004) caused about 30000 deaths (Poumadère et al., 2005) and adversely affected the human society and environments, causing the losses of large areas of forest, damages to water ecosystems and a relevant melting of glaciers in the European Alps. Severe heat wave events also occurred in July 2006 (central Europe), in 2007 summer (South-Eastern Europe) and in 2010 (Eastern Europe and Russia). Recently, Europe has been also affected by strong cold waves, such as the winter cold wave in 2005-2006 and the one occurred in February 2012.

A great number of works has been devoted to the analysis of trends in intensity and frequency of heat and cold waves (e.g. Brunetti et al., 2001; Griffiths et al., 2003; Alexander et al., 2006; Spinoni et al., 2015). The IPCC Special Report on extreme events (IPCC, 2012) stated that a major increase of warm extreme temperatures in Mediterranean region has been observed in the last three decades. Della-Marta et al. (2007), using a dataset consisting of 54 homogenized temperature time series collected in Europe, concluded that the length of heat waves has doubled and that the frequency of hot days has been tripled since 1880 .

The atmospheric circulation of the northern Atlantic has been identified as the main large-scale forcing of the extreme 
temperature events occurred in Europe and in the Mediterranean basins (e.g. Xoplaki et al., 2003; Santos and CorteReal, 2006). According to the results achieved by the studies of Cassou et al. (2005) and Carril et al. (2008), the anticyclonic circulation over the eastern North Atlantic plays a relevant role in the triggering of heat waves in Europe. Furthermore, linkages between the occurrence of extreme events and the North Atlantic Oscillation have been reported by Santos et al. (2007) and by Scaife et al. (2008). In a recent study, Andrade et al. (2012) have discovered a relevant connection between the winter variability of the cold nights and warm days in Europe and the dipolar pattern associated to the North Atlantic Oscillation. Moreover, this work has highlighted a relationship between the occurrence of summer warm days and the meridional pressure gradient over Europe: the presence of low-pressure systems over the northern Europe and, at the same time, of high-pressure systems over southern Europe is favourable to warm advection over the Mediterranean basins (Andrade et al., 2012).

In this study, we investigate about the variability and trends in the last 130 years of heat (HW) and cold wave $(\mathrm{CW})$ events, by analysing the temperature time series measured in Montevergine observatory $\left(40.56^{\circ} \mathrm{N}, 14.43^{\circ} \mathrm{E}\right)$. In this work, a HW event is defined as a period of a least three days in which the maximum and the minim temperature are simultaneously higher than the 90th percentile. In the same manner, a CW event is defined as a period of at least three days in which the maximum and the minim temperature are simultaneously below the 10th percentile.

Since it has been collected at $1280 \mathrm{~m}$ a.s.l., on the western side of Campania Apennines in the Southern Italy (Fig. 1a), Montevergine time series offers a valuable and unique opportunity to study the climatic changes, also in terms of extreme events, occurred in the past century at high-elevation sites in Central Mediterranean region. As highlighted by Abeli et al. (2012), the gradual increase of temperature, as well as the positive trends in extreme temperature events, have seriously affected the species and the ecosystem typical of mountain areas habitat. Therefore, a detailed study of the climatological time series collected in high-altitude sites can be very useful also to understand the implications of extreme temperature events on vegetation.

The HW and CW events occurred in Montevergine observatory between 1884 and 2015 have been examined in terms of frequency (FRE), duration (DUR), severity (SEV) and intensity (INT). The analysis, performed with respect to the yearly variability, has been carried out through the Wavelet Transform, in order to investigate about time series behaviour in time-frequency spectrum. We have performed also a linear trend analysis, evaluating the significance of the trends at $95 \%$ confidence level means of the Mann-Kendall test.

Moreover, we have explored the relationships between extreme temperature events occurred in Montevergine and the large-scale atmospheric patterns. The latter have been described through four different teleconnection indexes: the
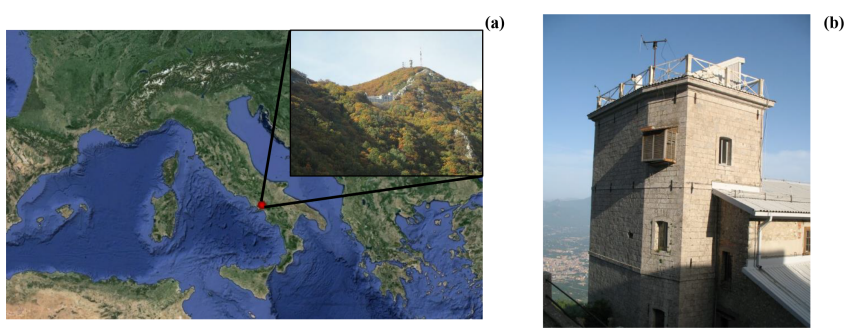

Figure 1. In panel (a), a map of Central Mediterranean region (courtesy of (C2016 Google), including Montevergine observatory location (highlighted as filled-in red circle) is show; in the right upper corner, a view of Montevergine abbey is presented. In panel (b), a picture of the Montevergine meteorological tower is displayed.

Eastern Mediterranean Pattern, the North Sea Caspian Pattern, the Western European Zonal Circulation and the North Atlantic Oscillation. This analysis, performed means of the Cross Wavelet Transform and the Wavelet Coherence, has allowed to understand the physical mechanisms that forced the variability and the oscillations in the time-frequency domain of HW and CW events.

Finally, we have characterized the synoptic circulation associated with summer HW events and winter $\mathrm{CW}$ events, by analysing the daily composites (retrieved through the reanalysis data provided by National Centers for Environmental Predictions-National Center for Atmospheric Research) of three different meteorological fields: the $500 \mathrm{hPa}$ geopotential height, the sea level pressure and the $700 \mathrm{hPa}$ relative humidity.

The paper is structured as follows. Section 2 provides information about the history of Montevergine observatory; it also describes the HW and CW indicators, the derived quantity (FRE, DUR, SEV and INT) and the methodologies used for the analysis of time series. Section 3 is dedicated to the discussion of the results, whereas Sect. 4 is devoted to the analysis of the relationships with large-scale atmospheric patterns. Conclusions are finally drawn together with perspectives for future research.

\section{Data and methodologies}

Montevergine observatory, hereafter MVOBSV, is the oldest among the high-altitude meteorological observatories located in Central and Southern Italy. It was founded in 1884 on the behest of the Barnabite Father Francesco Denza and has been managed by the Benedectine Community of Montevergine's Abbey. From 1884 to 1891, the observations were performed in a meteorological screen located at about $2 \mathrm{~m}$ above the ground. From 1892 to 2007, the weather measurements were performed in a screen located outside a northfacing window of the highest floor of a meteorological tower (Fig. 1b), built up at the suggestion of Italian Centre Office for Meteorology and Climate. From 2008 up to date, an 
Automatic Weather Station, installed on the Observatory terrace, has recorded the meteorological parameters.

The first results of the digitization of the climatic series, originally recorded on paper, have been presented in Diodato (1992) and in Budillon and Capozzi (2012); the latter study has analyzed the seasonal and yearly trends of temperature, total precipitation (rain and melted snow), atmospheric pressure and snowfall for the period 1884-1960. The results have highlighted a positive trend in annual mean temperature $\left(+0.2^{\circ} \mathrm{C} / 50\right.$ years) and a slight negative tendency in annual accumulated precipitation $(-50 \mathrm{~mm} / 50$ years $)$. In a subsequent study, Capozzi and Budillon (2013) have extended the analysis to the period 1884-2010, discovering an increase in yearly mean temperature $\left(+0.5^{\circ} \mathrm{C} / 100\right.$ years $)$ and a significant drop in annual total precipitation $(-32 \% / 100$ years).

The homogenization of temperature and total precipitation time series has been carried out using both direct and indirect approaches (Peterson and Easterling, 1994), according to the availability of metadata (i.e. the supplementary information about the observations, such as the type of instrument and the instrument location). The latter have been retrieved from meteorological registers and from an old diary named "Le Cronache dell'Osservatorio" (Capozzi and Budillon, 2013). Maximum (Tx) and minimum (Tn) temperature time series have been characterized by some discontinuities, arising from instruments relocation, changing in observation methods, human errors and instruments accuracy degradation. Those breaks in time series homogeneity have adversely affected the temperature records reliability in the following periods: 1884-1890, 1939-1951 and 1993-2001. Detailed information about the correction factor applied to correct the data measured in such sub-periods have been provided in Capozzi and Budillon (2013).

\subsection{Heat and cold waves indicators}

According to the guidelines provided by CLIVAR project, which is one of the four core projects of the World Climate Research Programme (WCRP; see www.clivar.org), the $\mathrm{HW}$ and $\mathrm{CW}$ indices can be grouped into four categories: percentile-based, duration-based, absolute-value based and threshold-based (Klein Tank et al., 2009). In our work, with the aim of future comparison between Montevergine time series and other climatological time series, we have considered the first two criteria, based on percentile and duration. The percentile criterion, as stated in Klein Tank et al. (2009), is suitable for spatial comparisons. Such index, in fact, regardless of the location considered, sample the same part of the probability distribution of a determined climatological variable. The indices based on absolute value do not allow the spatial comparison of extremes, because they may sample different parts of temperature distribution. The percentilebased indicator takes into account the temperature records above (or below) a certain percentile value, usually computed with respect to a 30 -year baseline period. The daily percentiles are computed considering a 5- or 15-day centred windows (e.g. Sillmann et al., 2013; Spinoni et al., 2015); the percentiles commonly refer to the 10th and the 90th levels (e.g. Zhang et al., 2011), although the available literature offers some variations, i.e. the $1 \mathrm{st}$, the $2 \mathrm{st}$ and the 5 th, and, oppositely, the 98th and the 99th (e.g. Díaz et al., 2006; Smith et al., 2013). The criterion based on duration considers the period of a least a determined number of consecutive warm (or cold) days and warm (or cold) nights. Some authors use this indicator on a period of a least two, three, five or also more days (e.g. Baldi et al., 2006).

In this study, a combined night-time and daytime $\mathrm{HW}$ event and, separately, a combined night-time and day-time CW event have been defined as follows:

- a HW event occurs when Tn and Tx are above the 90th percentile for at least three consecutive nights and days, respectively;

- a CW event occurs when Tn and Tx are below the 10th percentile for at least three consecutive nights and days, respectively.

We have calculated the daily percentile thresholds versus the 1981-2010 baseline period on a 15-day centred window.

Once a HW or CW event has been identified, it has been assigned the DUR, the SEV and the INT. The first descriptor refers to the number of days the event lasted (minimum three days); the SEV is the sum, defined in absolute value and over the entire event, of the differences between the temperature value and the percentile level; the INT is the ratio between severity and duration. Subsequently, for the period 1884-2015 and for both HW and CW, we have calculated the corresponding frequency (FRE, which is simply the number of events), the average DUR, the average SEV and the average INT of the events relative to every single year.

For every time series of $\mathrm{HW}\left(\mathrm{HW}_{\mathrm{FRE}}, \mathrm{HW}_{\mathrm{DUR}}, \mathrm{HW}_{\mathrm{SEV}}\right.$ and $\left.\mathrm{HW}_{\mathrm{INT}}\right)$ and $\mathrm{CW}\left(\mathrm{CW}_{\mathrm{FRE}}, \mathrm{CW}_{\mathrm{DUR}}, \mathrm{CW}_{\mathrm{SEV}}\right.$ and $\mathrm{CW}_{\text {INT }}$ ) events, a linear trend analysis has been performed for the following sub-periods: 1884-1913, 19141943, 1944-1973 and 1974-2015. This subdivision of the time series into four different segments has allowed detecting the change of sign of linear trend and the weakening or the intensification of the same. The sub-periods are of no less 30-year length, in order to preserve their consistency from a climatological point of view.

The significance at $95 \%$ confidence level of the trends has been evaluated through the Mann-Kendall test (Mann, 1945; Kendall, 1962).

\subsection{Wavelet analysis}

The Wavelet analysis has been developed as an alternative approach to the classic short time Fourier Transform and it is very useful for geophysical time series trend and periodicities examination. The Wavelet analysis, allowing the decomposition of a series into the time-frequency domain, is the 
most appropriate method for climate records analysis, whose variability is typically regulated by nonstationary processes. The Wavelet tool, in comparison with other powerful methods, such as the Fourier Transformation, offers the possibility to discriminate not only the particular frequencies in a nonstationary time series, but also their location in time (Percival, 2002). Because of those relevant advantages, we have decided to apply the Wavelet Transforms (WT) to the temperature extreme events time series involved in this study, in order to detect their oscillation in the time-frequency spectrum.

The WT are usually grouped into two main categories (Grinsted et al., 2004): the Continuous Wavelet Transform (CWT) and the Discrete Wavelet Transform (DWT). The latter is particularly useful for purposes of noise reduction and data compression, whereas the CWT is suitable for display and analyse time and scale-dependent features of time series. Therefore, we briefly discuss only the CWT.

A wavelet function has zero mean and is localized in both time and frequency domains. The localization property of the wavelets, resulting from their limited time duration and frequency bandwidth, enables to represent a determined signal with few coefficients. Moreover, such property made the WT tool very suitable for the analysis of the signals, such as the climatological ones, whose spectral content changes over the time. The CWT is defined with respect to a specific wavelet: the most widely used, the Morlet, is defined as,

$\psi_{0}(\eta)=\pi^{-\frac{1}{4}} e^{i \omega_{0} n} e^{-\frac{1}{2}^{2}}$,

where $\eta=t / s$ is the dimensionless time parameter, $t$ is the time, $s$ is the scale of the wavelet (i.e. its duration) and $\omega_{0}$ is the dimensionless frequency parameter. The Morlet wavelet is a good choice for the purposes of this study and, in general, for features extraction aims, because it provides the right balance between time and frequency localization (Grinsted et al., 2004). The wavelet is applied to a time series as a sort of band-pass filter and is stretched in time, by varying its scale $(s)$ and normalizing it to have unit energy. In particular, the CWT of a time series $\left(x_{n}, n=1, \ldots, N\right)$, is defined as the convolution of $x_{n}$ with the normalized and scaled wavelet:

$W_{n}^{X}(s)=\sqrt{\frac{\delta t}{s}} \sum_{n^{\prime}}^{N} x_{n^{\prime}} \psi_{0}\left[\left(n^{\prime}-n\right) \frac{\delta t}{s}\right]$,

where $n$ is the time index of the time series $\left(x_{n}, n=\right.$ $1, \ldots, N), \delta t$ is uniform time step of $x_{n}$ and the complex argument of $W_{n}^{X}(s)$ can be considered as the local phase. The wavelet power is defined as $\left|W_{n}^{X}(s)\right|$.

Because the wavelet is not totally localized in time, the CWT presents some deficiencies at the edges of the investigated time series. Therefore, it is useful to introduce a cone of influence, named COI, in which the edge effect cannot be disregarded. Following Grinsted et al. (2004), we have considered the COI as the area in which the wavelet power determined by a discontinuity at the edge has fallen down to $e^{-2}$ of the value at the border. The statistical significance of wavelet power has been assumed with respect to the null hypothesis that the signal is generated by a stationary process with a determined background power spectrum.

The CWTs of two different signals can be combined to determine the Cross Wavelet Transform (XWT) and the Wavelet Coherence (WTC). The first one allows to detect the areas, in the time-frequency space, where the two CWTs have common power and relative phase (Grinsted et al., 2004). The XWT of two determined time series, named $X_{n}$ and $Y_{n}$, is defined as:

$W^{X Y}=W^{X} W^{Y^{*}}$,

where ${ }^{*}$ is the complex conjugation (Grinsted et al., 2004). The complex argument $\arg \left(W^{X Y}\right)$ represents the local relation phase between the time series $\left(X_{n}\right.$ and $\left.Y_{n}\right)$ in the timefrequency domain.

The WTC can be useful to detect significant coherence between two different signals even if their common power is low. From a mathematical perspective, the WTC is defined as follows (Torrence and Webster, 1999):

$$
R_{n}^{s}(s)=\frac{\left|S\left(s^{-1} W_{n}^{X Y}(s)\right)\right|^{2}}{S\left(s^{-1}\left|W_{n}^{X}(s)\right|^{2}\right) \cdot S\left(s^{-1}\left|W_{n}^{Y}(s)\right|^{2}\right)},
$$

where $S$ is a smoothing operator and $R_{n}^{s}(s)$ ranges between 0 and 1. According to the definition given in Eq. (4), the WTC can be interpreted as a localized correlation in time-frequency domain between two time series (Grinsted et al., 2004). The smoothing operator $S$ can be written as:

$S(W)=S_{\text {scale }}\left(S_{\text {time }}\left(W_{n}(s)\right)\right)$,

where $S_{\text {time }}$ denotes the smoothing in time and $S_{\text {scale }}$ the smoothing with respect to wavelet scale axis. For the Morlet Wavelet, a suitable choice for the smoothing operator has been provided by Torrence and Webster (1999). The estimation of the statistical significance level of the WTC is carried out through the Monte Carlo method (for details, see Grinsted et al., 2004).

A Matlab package available from Grinsted et al. (2004), accessible through the website http://www.glaciology.net/ wavelet-coherence, has been used for the wavelet, cross wavelet and wavelet coherence analysis.

\subsection{Teleconnection patters}

In this work, the synoptic scale circulation has been represented through the following Northern Hemisphere teleconnection patterns: the Eastern Mediterranean Pattern (EMP), the North Sea Caspian Pattern (NSCP), the Western European Zonal Circulation (WEZC) and the North Atlantic Oscillation (NAO). Those indices have been selected according to their relevant influence on Mediterranean temperature regime, not only in terms of mean air temperature (e.g. 
Glowienka-Hense, 1990; Slonosky et al., 2001; Hatzaki et al., 2009; Brunetti and Kutiel, 2011), but also of extreme temperature values (e.g. Santos and Corte-Real, 2006; Andrade et al. 2012).

The EMP index has been introduced by Hatzaki et al. (2007) and is defined as the difference in $500 \mathrm{hPa}$ geopotential height (Z500) between the North-eastern Atlantic $\left(52.5^{\circ} \mathrm{N}, 25^{\circ} \mathrm{W}\right)$ and the Eastern Mediterranean $\left(32.5^{\circ} \mathrm{N}\right.$, $\left.22.5^{\circ} \mathrm{E}\right)$. The atmospheric patterns described by this index mainly emerge from October to April (Hatzaki et al., 2007) and exhibit a positive and a negative phase. The first one is associated to an intensification of the Atlantic anticyclone, which determined a prominent northern flow toward central Mediterranean basins. On the contrary, the negative phase implies an intensification of the Atlantic zonal flow over the central and western European regions.

The NSCP teleconnection index, introduced by Kutiel and Benaroch (2002), is defined as the difference in Z500 between the North Sea $\left(55^{\circ} \mathrm{N} / 0-10^{\circ} \mathrm{E}\right)$ and the Caspian $\left(45^{\circ} \mathrm{N} / 50-60^{\circ} \mathrm{E}\right)$. The negative phase of this index is associated to a cyclonic circulation around the North Sea and to an anticyclonic regime around the Caspian; because of this pattern, an intensification of southern flow in the regions that lie between North Sea and Caspian is observed (Brunetti and Kutiel, 2011). The positive phase determined an opposite atmospheric pattern, which enhances a northerly circulation.

The WEZC index has been introduced by Slonosky et al. (2001) and is defined as the difference in sea level pressure (SLP) between southern Europe (Madrid and Barcelona) and northern Europe (Trondheim and Lund). The positive phase of WEZC is associated to a strengthening of the westerlies over northern Europe and to anticyclonic conditions over central and western Mediterranean basins. On the contrary, the negative phase results in a strong weakening of the zonal flow over central Europe, in anticyclone circulation over Eastern Europe and in a cyclonic circulation over central Mediterranean basins.

The NAO index has been originally developed by Wallace and Gutzler (1981) and consists of a north-south dipole of SLP anomalies. One centre is located over Greenland, whereas the opposite one spans the central latitudes of the North Atlantic $\left(35-40^{\circ} \mathrm{N}\right)$. The positive phase of NAO index is associated to a strengthening of cyclonic circulation located over high-latitudes of the North Atlantic and of the anticyclone that crosses the mid-latitudes of the North Atlantic; these anomalies are favourable to an intensification of western flow over central and northern Europe. The negative phase results in an opposite pattern of anomalies and enhances cyclonic conditions over central and western Mediterranean basins and the development of a high-pressure system over eastern Europe.

The EMP, the NSCP and the WEZC teleconnection patterns have been reconstructed for every month of the 18842015 period, means of the reanalysis data provided by $\mathrm{Na}-$ tional Centers for Environmental Predictions-National Cen- ter for Atmospheric Research (NCEP-NCAR). More specifically, for the 1884-2012 period, the NCEP/NCAR 20th Century Reanalysis data, archived in grids of resolution $2.0^{\circ}$ latitude $\times 2.0^{\circ}$ longitude, have been used (Compo et al., 2011). For the 2013-2015 period, due to the unavailability of 20th Century Reanalysis dataset, the $2.5^{\circ} \times 2.5^{\circ}$ resolution gridded dataset NCEP/NCAR Reanalysis 1 has been adopted (Kalnay et al., 1996). For each teleconnection index, the monthly time series have been standardized with respect to 1981-2010 climatology and averaged on yearly basis. Regarding the NAO index, the data provided by Climate Research Unit (Brohan et al., 2006), standardized relative to 1981-2010 period, have been used.

The time series and the respective CWT spectra of the four teleconnection indices just illustrated are sketched in Fig. 2. In the last three decades, the EMP index has exhibited a predominant neutral or negative phase (Fig. 2a). The Wavelet spectrum of EMP, presented in Fig. 2c, has highlighted relevant fluctuations between 1900 and 1960 in the 8-14-year band; some significant oscillations, associated to lower periodicities, have been observed also around 1950 and around 1980. The NSCP index has shown significant power between 1905 and 1920 (in the 2-4-year band) and around 1920 (on a period of about 8 years), as revealed by Fig. 2 d. The WEZC and the NAO indexes have been both characterized by a prevalent positive phase between 1980s and 1990s (Fig. 2e and f) and by relevant fluctuations between 1990s and 2010 in the 1-8-year band (Fig. $2 \mathrm{~g}$ and h). Moreover, the WEZC spectrum has exhibited significant oscillations also between 1930 and 1970 in the 3-7-year band.

\section{Results}

This section presents the results obtained for every descriptor used to analyze the yearly variability and trends of HW and CW events occurred in MVOBSV.

According to Fig. 3, the HWFRE time series has shown an increasing trend of 1.16 events every 10 years in the last four decades (1974-2015); this strong and significant trend is also highlighted by Table 1 . The Wavelet Analysis has exhibited significant oscillations of HW $\mathrm{HRE}_{\mathrm{F}}$ signal around 1980 and around 2000 on a period of 2-4 years; furthermore, an area of strong power has been detected between 1990 and 2000 , on a period of about $4-6$ years. The CW $\mathrm{WRE}_{\text {FRe se- }}$ ries has shown a negative but no significant tendency in the last sub-period. The CWT of $\mathrm{CW}_{\text {FRE }}$ signal has pointed out some oscillations in the 2-4-year band; in particular, a total of three strong power areas has been detected: the first one is located around 1930, the second one in the 1940-1945 period and the third one around 1960.

The $\mathrm{HW}_{\text {DUR }}$ and the $\mathrm{CW}_{\text {DUR }}$ time series (Fig. 4) do not show any significant trend in the four sub-periods analyzed. The CWTs of the two signals has highlighted some interesting features, instead. Regarding the $\mathrm{HW}_{\text {DUR }}$, six areas of 

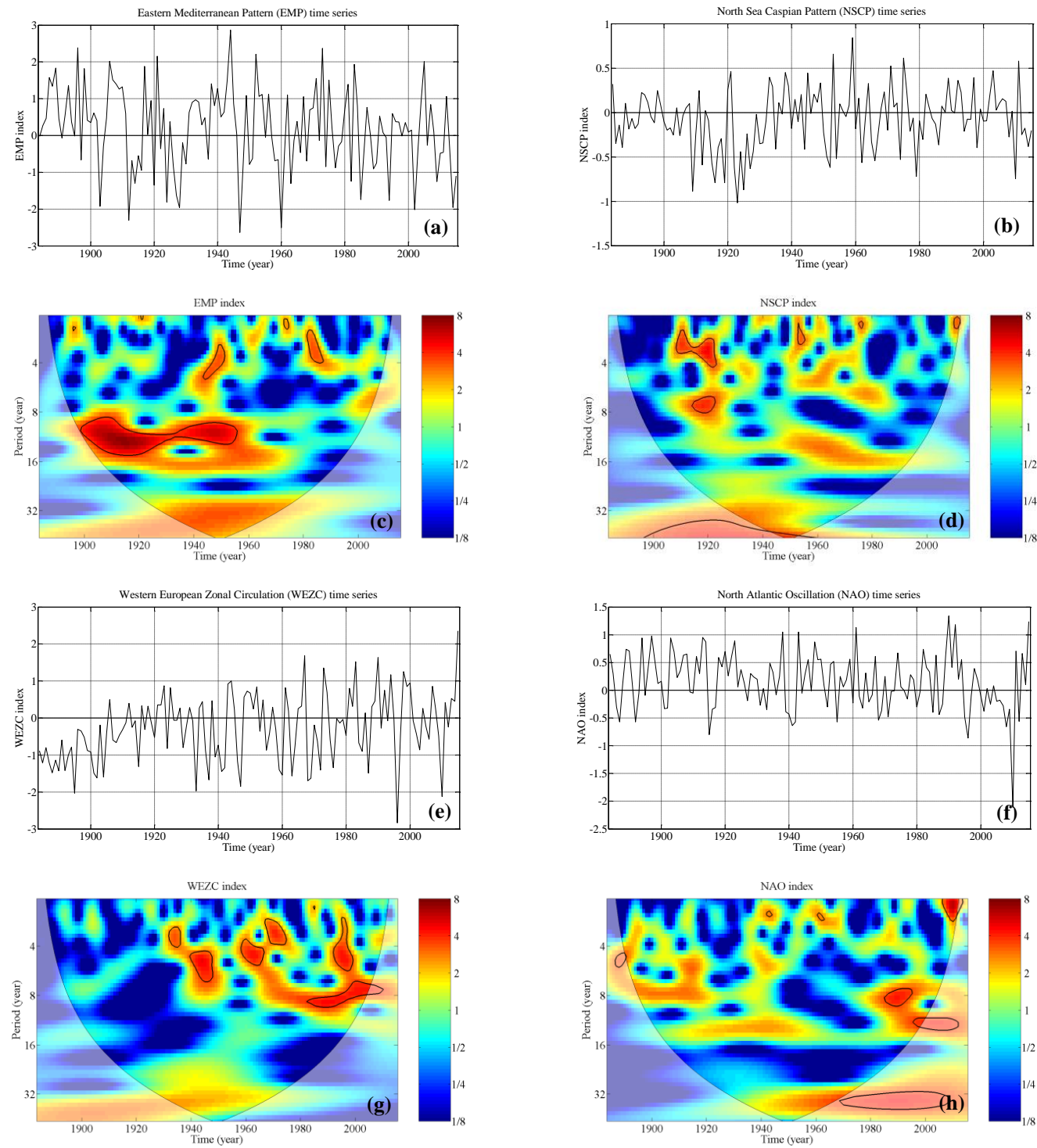

Figure 2. Annual time series and Continuous Wavelet Transform (CWT) analysis of the four teleconnection indexes involved in this study (1884-2015 period): the Eastern Mediterranean Pattern (a, c), the North Sea Caspian Pattern (b, d), the Western European Zonal Circulation $(\mathbf{e}, \mathbf{g})$ and the North Atlantic Oscillation $(\mathbf{f}, \mathbf{h})$. The indexes have been standardized with respect to 1981-2010 period. The thick contour on CWT plots designates the $5 \%$ significance level against red noise; the cone of influence, where edge effects might distort the picture, is shown as a lighter shade.

high-power in the band of 1-5 years have been detected between 1910 and 1980. The Wavelet Analysis has also pointed out significant oscillations over longer periods. In particular, an area of strong power has been found in 1940-1960 period in the 4-6-year band and around 12-year band. The Wavelet spectrum of $\mathrm{CW}_{\text {DUR }}$ signal has exhibited areas of strong power completely located outside the COI only in the high-frequencies region. More specifically, a strong power has been detected between 1910 and 1920 (period 2-5 years), around 1950 (period 1-2 years), 1980 (in the 2-year band) and 2000 (period $1-2$ years).
The $\mathrm{HW}_{\mathrm{SEV}}$ and $\mathrm{CW}_{\mathrm{SEV}}$ time series are presented in Fig. 5. The HW $\mathrm{HEV}_{\mathrm{SEV}}$ signal has shown a positive and significant trend of 1.15 SEV score per decade in the last 40 years. The CWT of $\mathrm{HW}_{\mathrm{SEV}}$ has revealed several different regions of high power between 1900 and 1980, located in the 1-5-year band. An area of strong power, although partially located in the COI, has been also detected in 1900-1920 on a period of about $14-16$ years. For the $\mathrm{CW}_{\mathrm{SEV}}$ signal, no significant trends have been discovered, albeit a positive tendency has been observed in the last sub-period (1974-2015). The CWT has exhibited oscillations on 1-2-year band between 1940 and 1960 and around 2000. Two areas of high power have 

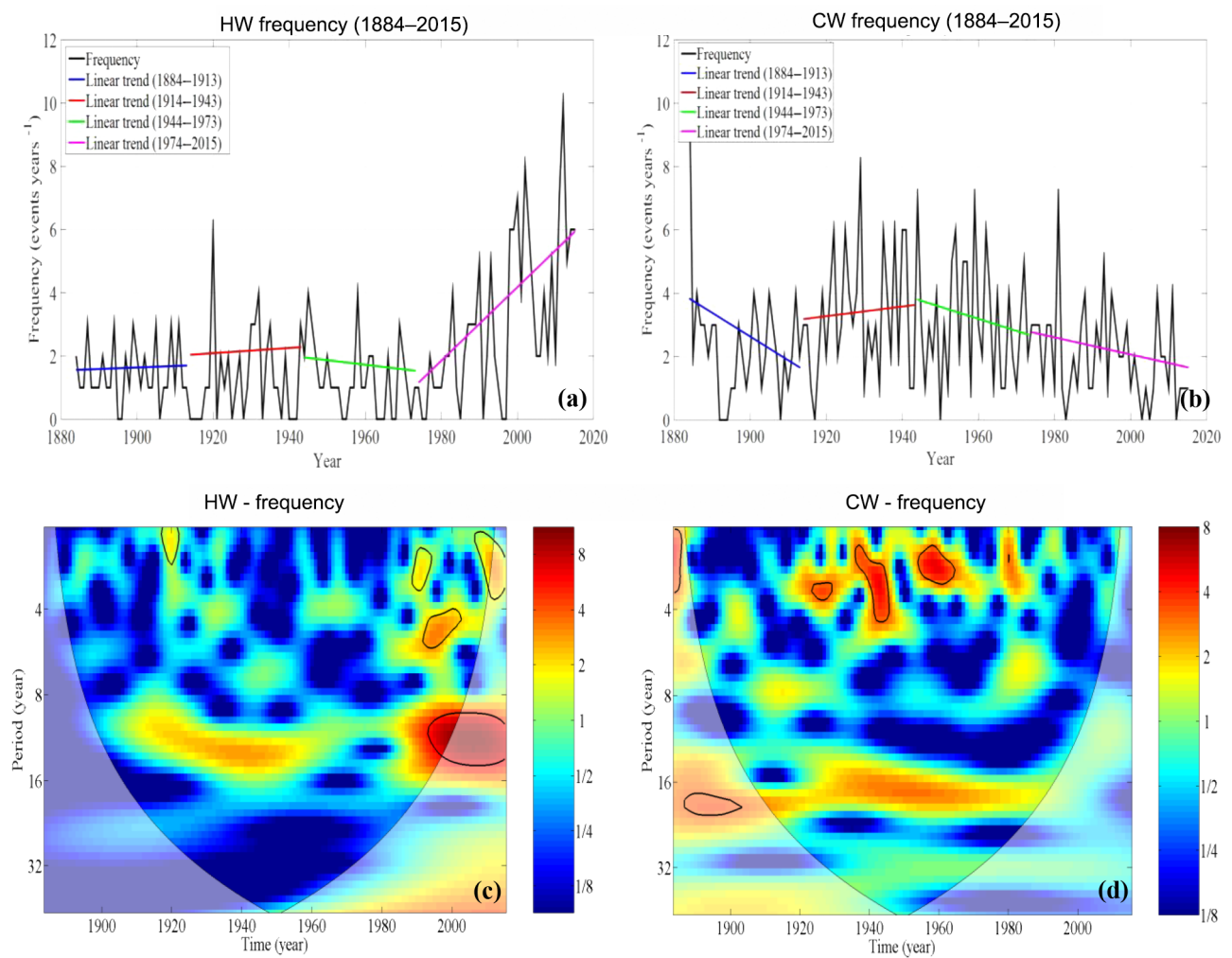

Figure 3. In the upper panels, (a) and (b), heat wave events (HW) and cold wave events $(\mathrm{CW})$ frequency (events year ${ }^{-1}$ ) time series for the period 1884-2015 are presented. In the bottom panels, (c) and (d), the CWTs of the two time series are shown. The thick contour designates the $5 \%$ significance level against red noise; the cone of influence, where edge effects might distort the picture, is shown as a lighter shade.

Table 1. Annual linear trends values, for different sub-periods, of heat wave events (HW) frequency, duration, severity and intensity; all values are per decade. Linear trend values significant at $95 \%$ are marked with an asterisk.

\begin{tabular}{lrrrr}
\hline Period & \multicolumn{4}{c}{ Linear trends in Heat Wave events (HW) } \\
\cline { 2 - 5 } & $\begin{array}{r}\text { Frequency } \\
\text { (number of } \\
\text { events per } \\
\text { decade) }\end{array}$ & $\begin{array}{r}\text { Duration } \\
\text { (number of } \\
\text { days per } \\
\text { decade) }\end{array}$ & $\begin{array}{r}\text { Severity } \\
\text { (severity } \\
\text { score per } \\
\text { decade) }\end{array}$ & $\begin{array}{r}\text { Intensity } \\
\text { (intensity } \\
\text { score per } \\
\text { decade) }\end{array}$ \\
\hline $1884-1913$ & 0.04 & 0.19 & 0.94 & 0.09 \\
$1914-1943$ & 0.08 & 0.07 & -1.95 & $-0.46^{*}$ \\
$1944-1973$ & -0.14 & -0.02 & 0.09 & 0.00 \\
$1974-2015$ & $1.16^{*}$ & 0.13 & $1.15^{*}$ & $0.17^{*}$ \\
\hline
\end{tabular}

been also detected over longer period (4-8 years): one is located between 1900 and 1910, the other one around 1960 .

The $\mathrm{HW}_{\text {INT }}$ and $\mathrm{CW}_{\text {INT }}$ time series are characterized by a similar positive and significant tendency ( 0.17 and 0.33 INT score per decade, respectively) in the last decades (Fig. 6). Moreover, as highlighted by Tables 1 and 2, HW INT and $\mathrm{CW}_{\text {INT }}$ signals have exhibited a significant but opposite tendency ( -0.46 INT score per decade and 0.28 INT score per decade, respectively) in the 1914-1943 period. The CWT
Table 2. Annual linear trends values, for different sub-periods, of cold wave events (CW) frequency, duration, severity and intensity; all values are per decade. Linear trend values significant at $95 \%$ are marked with an asterisk.

\begin{tabular}{lrrrr}
\hline Period & \multicolumn{3}{c}{ Linear trends in Cold Wave events (CW) } \\
\cline { 2 - 5 } & $\begin{array}{r}\text { Frequency } \\
\text { (number of } \\
\text { events per } \\
\text { decade) }\end{array}$ & $\begin{array}{r}\text { Duration } \\
\text { (number of } \\
\text { days per } \\
\text { decade) }\end{array}$ & $\begin{array}{r}\text { Severity } \\
\text { (severity } \\
\text { score per } \\
\text { decade) }\end{array}$ & $\begin{array}{r}\text { Intensity } \\
\text { (intensity } \\
\text { score per } \\
\text { decade) }\end{array}$ \\
\hline $1884-1913$ & -0.74 & -0.01 & -1.15 & -0.19 \\
$1914-1943$ & 0.15 & 0.12 & 1.82 & $0.28^{*}$ \\
$1944-1973$ & -0.37 & 0.17 & 1.12 & 0.11 \\
$1974-2015$ & -0.27 & -0.12 & 0.84 & $0.33^{*}$ \\
\hline
\end{tabular}

of $\mathrm{HW}_{\mathrm{INT}}$ signal has highlighted some oscillations in highfrequencies regions between the 1900 and the 1970. Moreover, an area of strong power between 1900 and 2000 has been detected in 16-32-year band. The Wavelet spectrum of $\mathrm{CW}_{\text {INT }}$ has exhibited areas of high power between 1900 and 1920 in the 4-8-year band, as well as significant oscillations on 1-2-year period around 1950 and in the 1-4-year band (2000-2010 period). 

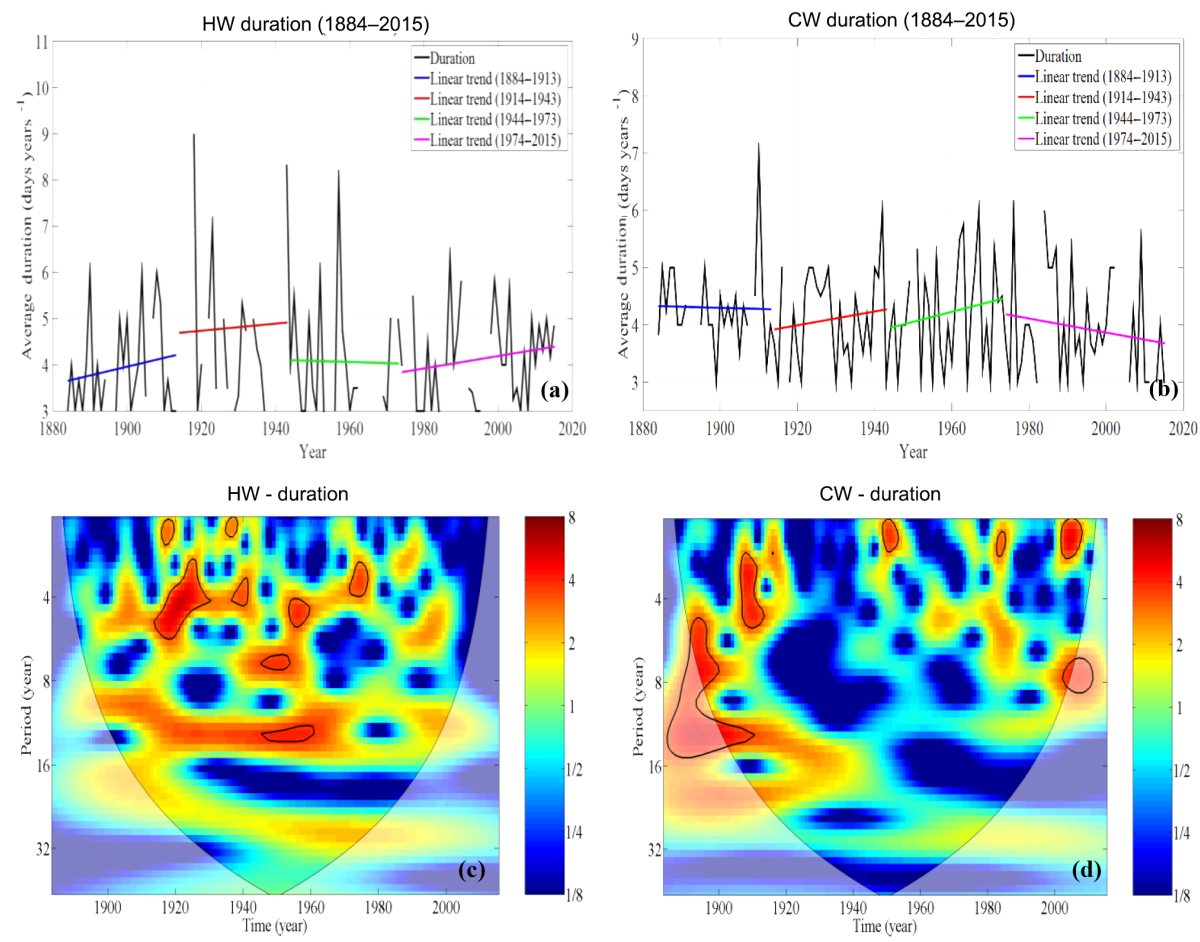

Figure 4. In the upper panels, (a) and (b), heat wave events (HW) and cold wave events (CW) duration (days years ${ }^{-1}$ ) time series for the period 1884-2015 are presented. In the bottom panels, (c) and (d), the CWTs of the two time series are shown. The thick contour designates the $5 \%$ significance level against red noise; the cone of influence, where edge effects might distort the picture, is shown as a lighter shade.
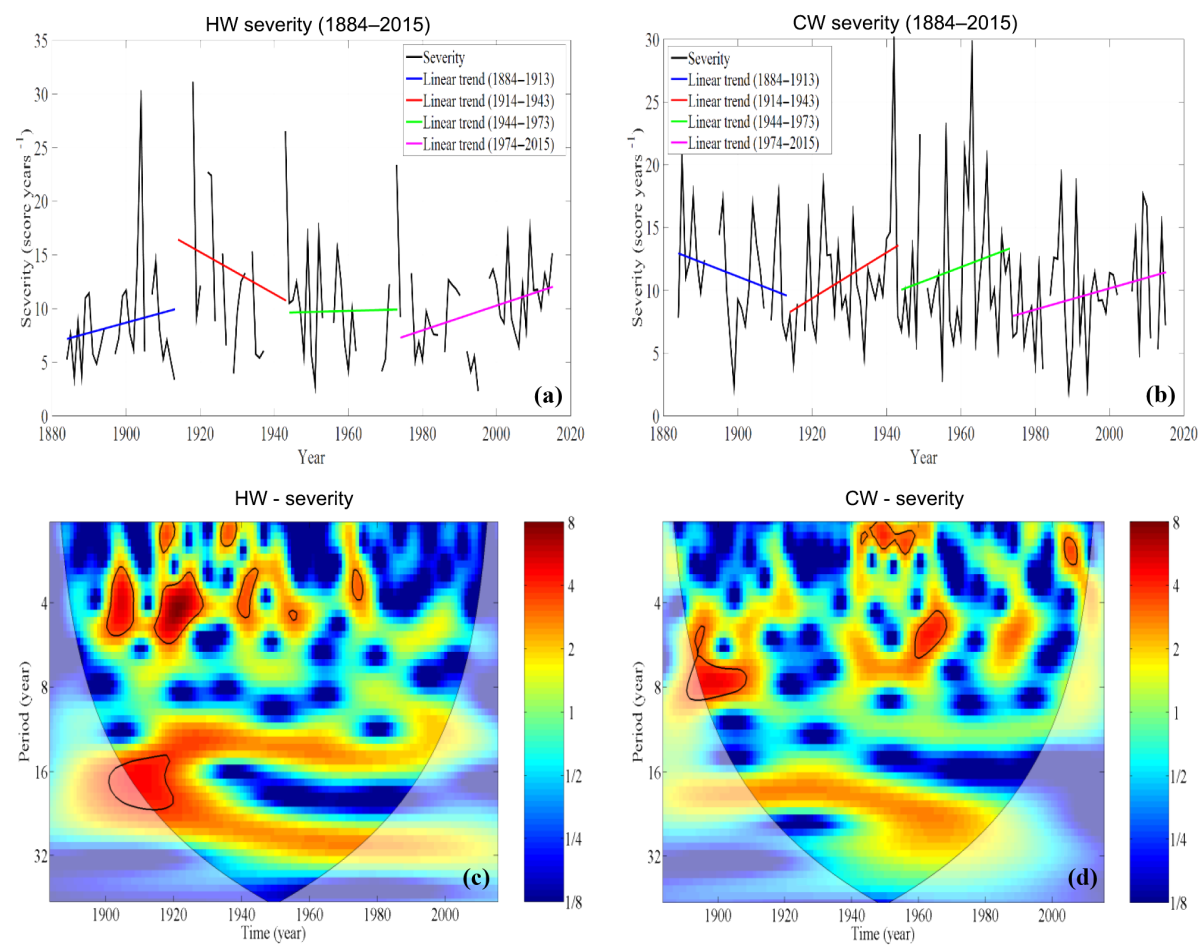

Figure 5. In the upper panels, (a) and (b), heat wave events (HW) and cold wave events (CW) severity (severity score years ${ }^{-1}$ ) time series for the period 1884-2015 are presented. In the bottom panels, (c) and (d), the CWTs of the two time series are shown. The thick contour designates the $5 \%$ significance level against red noise; the cone of influence, where edge effects might distort the picture, is shown as a lighter shade. 

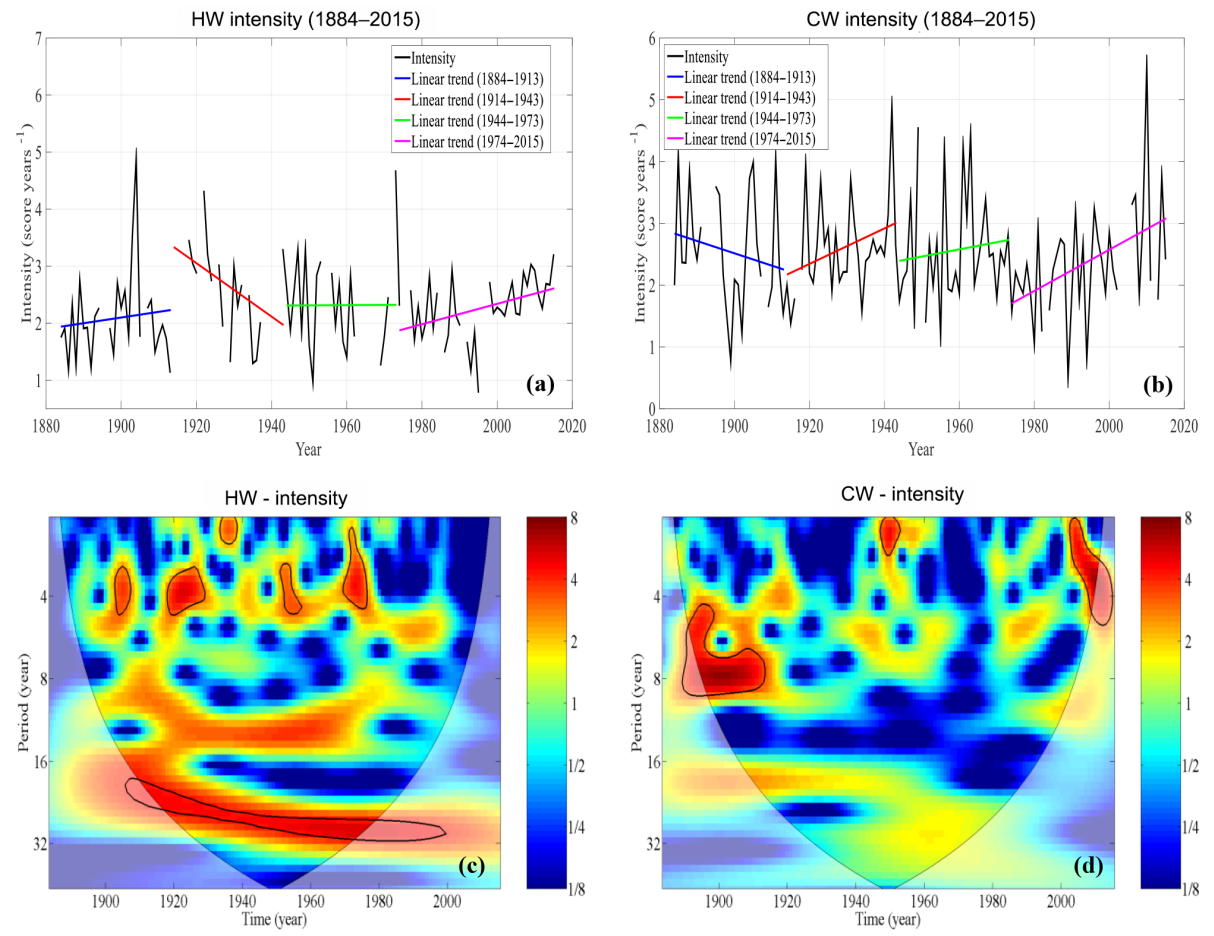

Figure 6. In the upper panels, (a) and (b), heat wave events (HW) and cold wave events (CW) intensity (intensity score years ${ }^{-1}$ ) time series for the period 1884-2015 are presented. In the bottom panels, (c) and (d), the CWTs of the two time series are shown. The thick contour designates the $5 \%$ significance level against red noise; the cone of influence, where edge effects might distort the picture, is shown as a lighter shade.

\section{Relationships with large-scale atmospheric patterns}

This section is devoted to the analysis of the linkages between HW and CW time series and the large-scale meteorological patterns. The relationships with the teleconnection indexes described in Sect. 2.3 are presented in terms of XWT and WTC spectra. The latter have been estimated for the same frequency bands used for the CWTs of the HW and $\mathrm{CW}$ time series.

To correctly interpreter XWT and WTC plots, it is important to point out that the relative phase relation of the two signals $(x$ and $y$ ) involved in a determined XWT or WTC analysis is shown by arrows. According to Grinsted et al. (2004), the direction of the arrows denotes the phase degree of the two investigated signals. Right arrows indicate a direct inphase relationship between $x$ and $y$, left arrows an anti-phase relationship, down arrows that $x$ leads $y$ by a phase angle of $90^{\circ}$ (which corresponds to a one fourth of the cycle at that period) and up arrows that $x$ lags $y$ by a phase angle of $90^{\circ}$. Moreover, as for CWTs plots, the COI is marked as a lighter shade and the areas in time-frequency domain where a $5 \%$ significance level against red noise has been detected are indicated by black thick contour.

In addition, this section presents the main features of synoptic patterns associated to summer $\mathrm{HW}$ and winter $\mathrm{CW}$ occurred in MVOBSV.

\subsection{Results for HW time series}

The variability of HW time series has shown a close connection with the fluctuations of the large-scale atmospheric patterns synthetized by WEZC and NAO indexes. The XWTs between $\mathrm{HW}$ time series (i.e. $\mathrm{HW}_{\mathrm{FRE}}, \mathrm{HW}_{\mathrm{DUR}}, \mathrm{HW}_{\mathrm{SEV}}$ and $\left.\mathrm{HW}_{\mathrm{INT}}\right)$ and the two teleconnections pattern just mentioned are presented in Fig. 7.

The HW FRE signal and WEZC (Fig. 7a) have exhibited common power between 1990 and 2000 over a period of $\cong 4$ years and in the 8-12-year band: both areas of large common power are characterized by a direct in-phase relationship between the two signals. Relevant common oscillations, albeit associated to lower power, have been detected also in 1940 and between 1960 and 1970, on a period of about 4 years. The $\mathrm{HW}_{\mathrm{FRE}}$ time series and NAO index (Fig. 7b) have shown common fluctuations from 1990 in the 8-12-year band: however, in this case $\mathrm{HW}_{\mathrm{FRE}}$ signal leads NAO index by approximatively $45^{\circ}$ (which corresponds to a lead time of about 1 year). Another area of common power has been detected in the high-frequency region (1-4 years) after the year 2000.

The HW DUR oscillations have exhibited a close in-phase connection with WEZC (Fig. 7c) mainly in the 3-8-year band. NAO and HW DUR spectra have exhibited common features between 1920 and 1960 and after 1990 in the 10-12- 

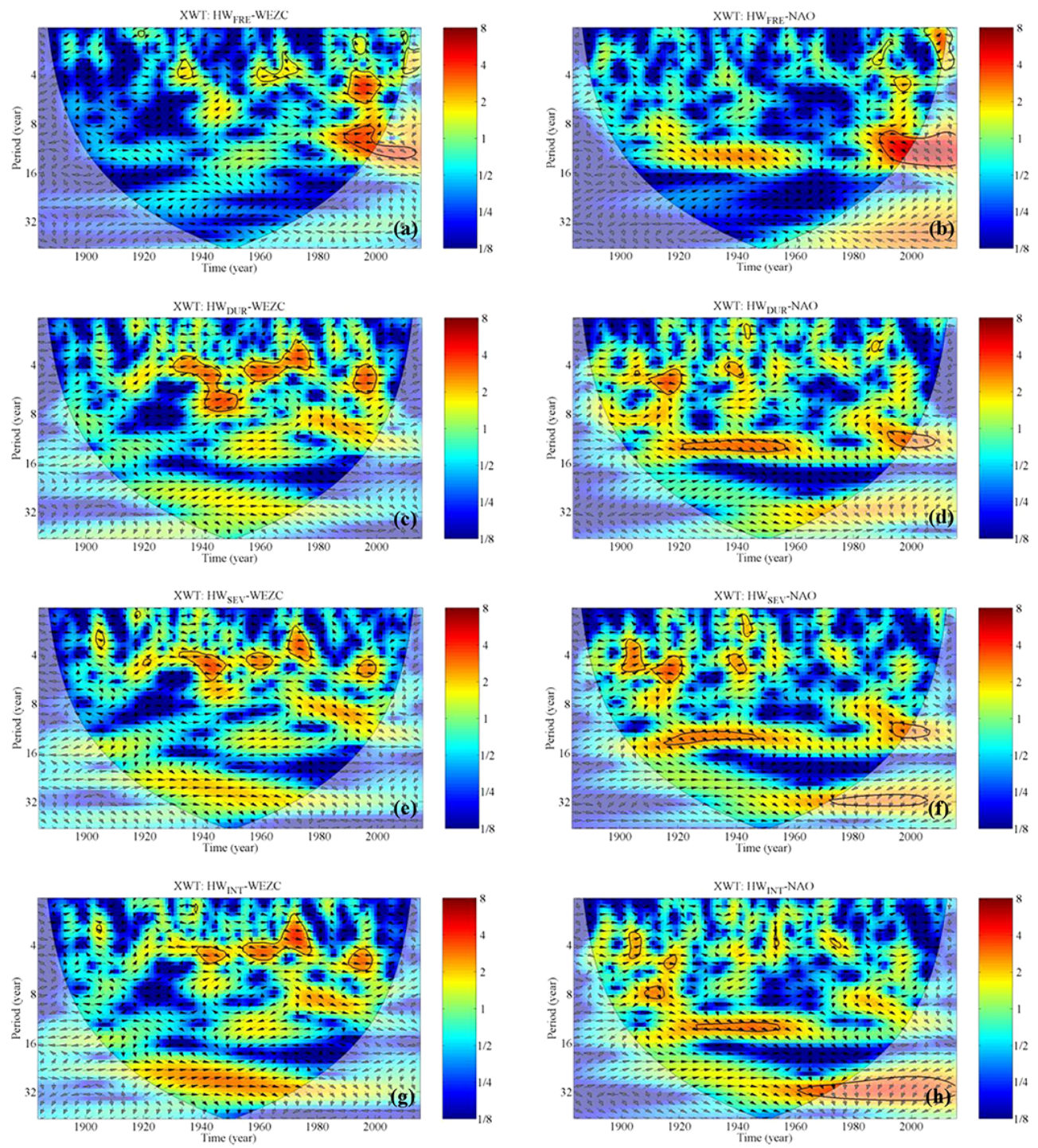

Figure 7. In the left panels, (a, c, e, g), the Cross Wavelet Transform (XWT) spectra between HW events time series, i.e. HW FRE $_{\text {, HW }}$ DUR, $\mathrm{HW}_{\mathrm{SEV}}$ and HW $\mathrm{HNT}_{\mathrm{INT}}$, and WEZC index are presented (1884-2015 period). In the right panels, (b, d, f, h), the XWT spectra between HW events time series and NAO index are shown. The black arrows indicate the phase relationship between the respective time series. The thick contour designates the $5 \%$ significance level against red noise; the cone of influence, where edge effects might distort the picture, is shown as a lighter shade. All XWT spectra refer to the period 1884-2015.

year band (Fig. 7d); in both areas of high common power, $\mathrm{HW}_{\text {DUR }}$ leads NAO by a phase angle of about $45^{\circ}$.

Figure $7 \mathrm{e}$ highlights strong common power between HW $_{\text {SEV }}$ and WEZC between 1930 and 1990 in the 3-5-year band: a direct in-phase relationship between the two signals has been observed, as indicated by the black arrows. The strong oscillations of $\mathrm{HW}_{\mathrm{SEV}}$ signals detected before 1930, discussed in Sect. 3 and marked by Fig. 5c, are in-phase with the fluctuations of NAO index, as shown by Fig. 7f. An area of high common power between $\mathrm{HW}_{\mathrm{SEV}}$ and NAO spectra has been also detected over longer period ( $\cong 14$ years) between 1920 and 1950.
The $\mathrm{HW}_{\text {INT }}$ and WEZC time series have exhibited a strong in-phase linkage around 1940, between 1950 and 1980, and around 1990 over a period of about $2-5$ years (Fig. $7 \mathrm{~g}$ ). The oscillations of HW INT signal observed before 1940, in the 3-5-year band, can be related to NAO variability, as shown by Fig. $7 \mathrm{~h}$. The Wavelet spectra of $\mathrm{HW}_{\mathrm{INT}}$ and NAO signals have common features also between 1930 and 1950, on a period of approximatively 14 years; also in this case, $\mathrm{HW}_{\text {INT }}$ signal leads NAO index by a phase angle of about $45^{\circ}$.

The WTC analysis has revealed a relevant coupling between HW time series and NAO index, as illustrated by Fig. 8. The $\mathrm{HW}_{\mathrm{FRE}}, \mathrm{HW}_{\text {DUR }}$ and $\mathrm{HW}_{\mathrm{SEV}}$ signals have exhibited a significant coherence with NAO in the 12-16-year 

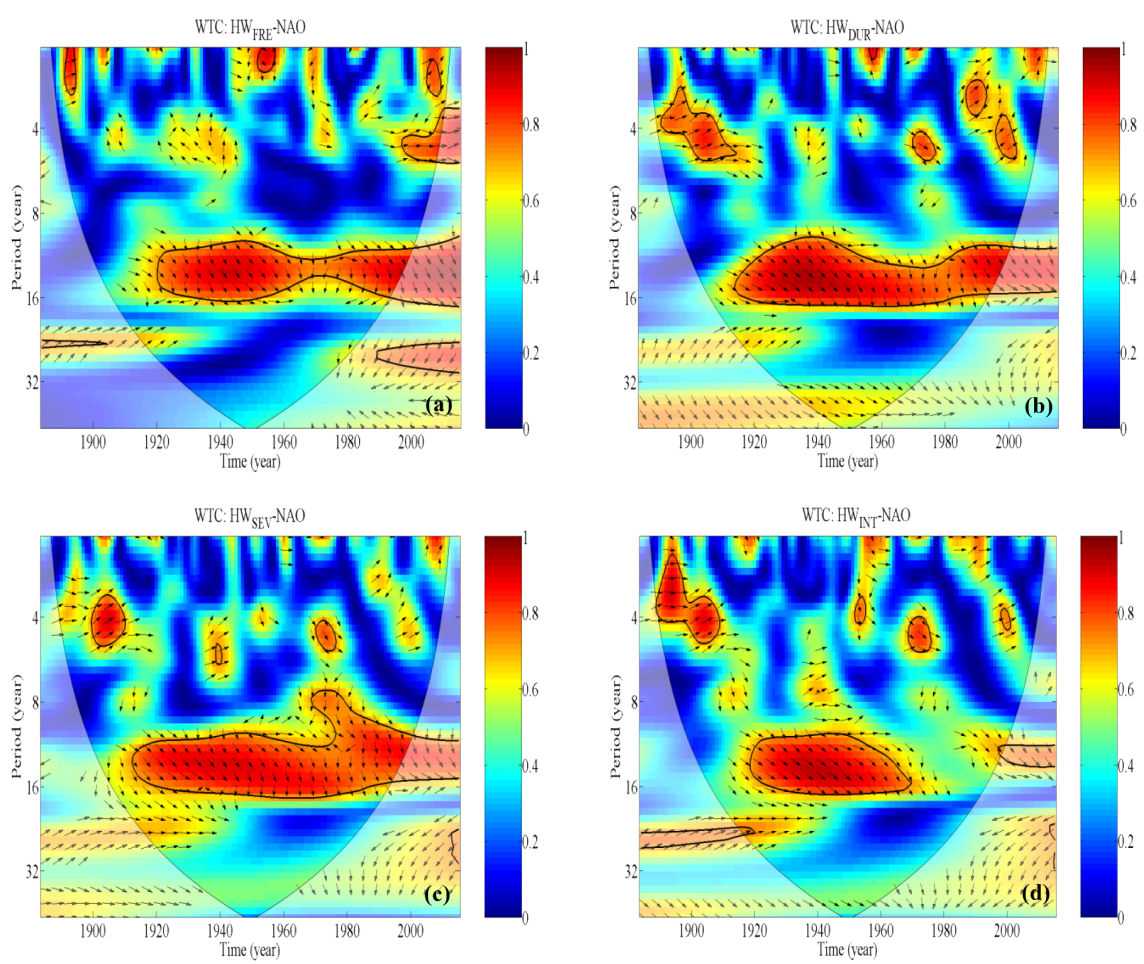

Figure 8. Wavelet Coherence (WTC) spectra between HW events time series, i.e. HW FRE (a), HW DUR $_{\text {(b), HW }}$ SEV (c) and HW INT $($ d), and NAO index for the 1884-2015 period. The black arrows indicate the phase relationship between the respective time series. The thick contour designates the $5 \%$ significance level against red noise; the cone of influence, where edge effects might distort the picture, is shown as a lighter shade. Colors indicate the strenght of coherence, which ranges between a minimum of 0 and a maximum of 1 . All WTC spectra refer to the period $1884-2015$.

band from 1920 up to 2000 years. However, in this area of high covariance, the NAO cycles lag those of the three HW descriptors just mentioned by a phase angle ranging between 45 and $90^{\circ}$, which correspond to a time lag of about 3.5 years. Regarding the $\mathrm{HW}_{\text {INT }}$ signal (Fig. 8d), the area of high covariance with NAO index detected in the 12-16-year band includes only the 1920-1970 period, with a phase-relationship very similar to the one just discussed. For lower periodicities (i.e. 1-8-year band), some areas of significant coupling, associated to a direct in-phase linkage, have been found between 1900 and 1920 and after 1960.

The results just discussed suggest that the prevalent positive phase of WEZC and NAO indexes observed between 1980s and 1990s has exerted a relevant influence on the upward tendency of $\mathrm{HW}_{\mathrm{FRE}}, \mathrm{HW}_{\mathrm{SEV}}$ and $\mathrm{HW}_{\mathrm{INT}}$ detected in the last four decades (1974-2015). The synoptic scenarios associated to the positive phase of these two teleconnection indexes, as discussed by previous studies (e.g. Cassou et al., 2005; Andrade et al., 2012), are often associated to the advection of sub-tropical air masses in the Mediterranean regions.

\subsection{Results for CW time series}

The $\mathrm{CW}_{\mathrm{FRE}}$ and the $\mathrm{CW}_{\text {DUR }}$ time series have exhibited a considerable linkage with the EMP index. As shown by Fig. 9a, the XWT spectrum between $\mathrm{CW}_{\mathrm{FRE}}$ and EMP presents areas of common power between 1940 and 1950 (in the 4-year band), around 1960 and 1980 (in the 2-3-year band). In the first area, the two signals are in a direct inphase relationship, whereas in the second ones the EMP leads $\mathrm{CW}_{\mathrm{FRE}}$ signal with a phase angle ranging between 45 and $90^{\circ}$ (which corresponds to a lead-time of about 4-7 months). Moreover, an area of common power has been also detected in 16-year band, between 1930 and 1960; in this case, the EMP cycle leads the one of $\mathrm{CW}_{\mathrm{FRE}}$ with a phase angle of approximatively $45^{\circ}$, which corresponds to a lead time of 2 years. The XWT between $\mathrm{CW}_{\text {DUR }}$ and EMP (Fig. 9b) has revealed an area of strong common power between 1900 and 1930 in the 12-16-year band. The two signals, in this area, have exhibited a weak anti-phase relationship: the orientation of the black arrows, in fact, indicates that $\mathrm{CW}_{\text {DUR }}$ leads EMP with a phase angle of about $45^{\circ}$. Other areas of common fluctuations have been detected in the 1-4-year band around 1950, 1970 and 1980. 

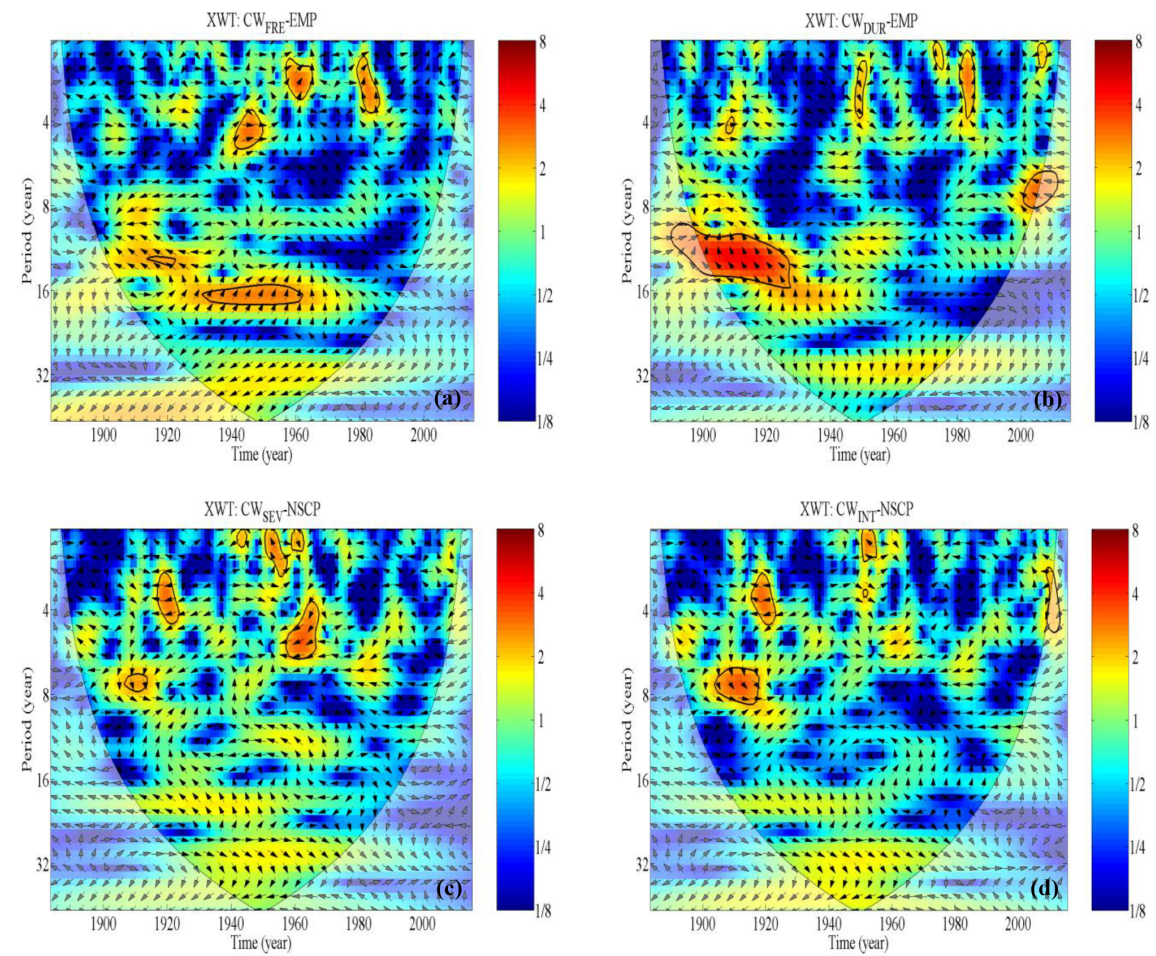

Figure 9. In the left panels, the Cross Wavelet Transform (XWT) spectra between $\mathrm{CW}_{\mathrm{FRE}}$ and EMP index (a) and between CW $\mathrm{SEV}$ and NSCP index (c) are presented. In the right panels, the XWT analysis between CW DUR and EMP index (b) and between CW INT and NSCP index (d) are sketched. The black arrows indicate the phase relationship between the respective time series. The thick contour designates the $5 \%$ significance level against red noise; the cone of influence, where edge effects might distort the picture, is shown as a lighter shade. All XWT spectra refer to the period 1884-2015.

The $\mathrm{CW}_{\mathrm{SEV}}$ and $\mathrm{CW}_{\mathrm{INT}}$ signals have shown relevant connections with NSCP index. Figure 9c highlights six areas of common power between $\mathrm{CW}_{\mathrm{SEV}}$ and NSCP spectra on periodicities lower than 8 years. The two signals have exhibited a clear anti-phase relationship around 1920 (in the 3-4-year band) and between 1960 and 1970 (on periodicities of about 4-6 years). The XWT analysis that involves $\mathrm{CW}_{\text {INT }}$ signal and NCSP has revealed common fluctuations around 1920 (on a period of about 3-4 years) and around 1950 (in the 12 -year band). In both areas of the time-frequency spectrum, an anti-phase relationship between the two signals has been discovered.

The relevant influence exerted by the atmospheric patterns synthetized by EMP and NSCP on CW signals is emphasized also by WTC spectra. Figure 10a shows a coupling between $\mathrm{CW}_{\mathrm{FRE}}$ and EMP on very long periods ( $>32$ years). The arrows orientation indicates a weak anti-phase correlation between the two signals: more specifically, the $\mathrm{CW}_{\mathrm{FRE}}$ signal leads EMP by a phase angle of about $45^{\circ}$, which corresponds to a lead-time of about 8 years. Other areas of high covariance, also associated to a weak anti-phase relationship, have been detected in the 1-4-year band around 1960 and 1990. Moreover, the WTC spectrum highlights significant covariance around 1920 , on a period of about 6-8 years: in this case, a clear anti-phase linkage between the two signals has been discovered. As shown by Fig. 10b, an area of high covariance between $\mathrm{CW}_{\text {DUR }}$ and EMP has been detected also between 1930 and 1940 (in the 5-7-year band) and between 1990 and 2000 (for periodicities ranging between 5 and 9 years): in both cases, the two signals are in anti-phase relationship. The $\mathrm{CW}_{\mathrm{SEV}}$ and $\mathrm{CW}_{\mathrm{INT}}$ signals have exhibited a relevant coupling with NSCP index between 1920 and 1940 (in the 3-6-year band) and between 1970 and 2000 (on a period of $\cong 8-9$ years): in both cases, the detected cycles are in anti-phase relationship.

The other teleconnection patterns considered in this study (WEZC and NAO) do not show relevant linkages with CW time series variability, both in terms of phase relationship and covariance.

\subsection{Synoptic circulation associated to summer HW events and to winter $\mathrm{CW}$ events}

In this paragraph, we present the main characteristics of synoptic patterns associated to summer $\mathrm{HW}$ and winter $\mathrm{CW}$ events. The summer HW (hereafter, SHW) include the HW events occurred from June to August in the period 1884- 

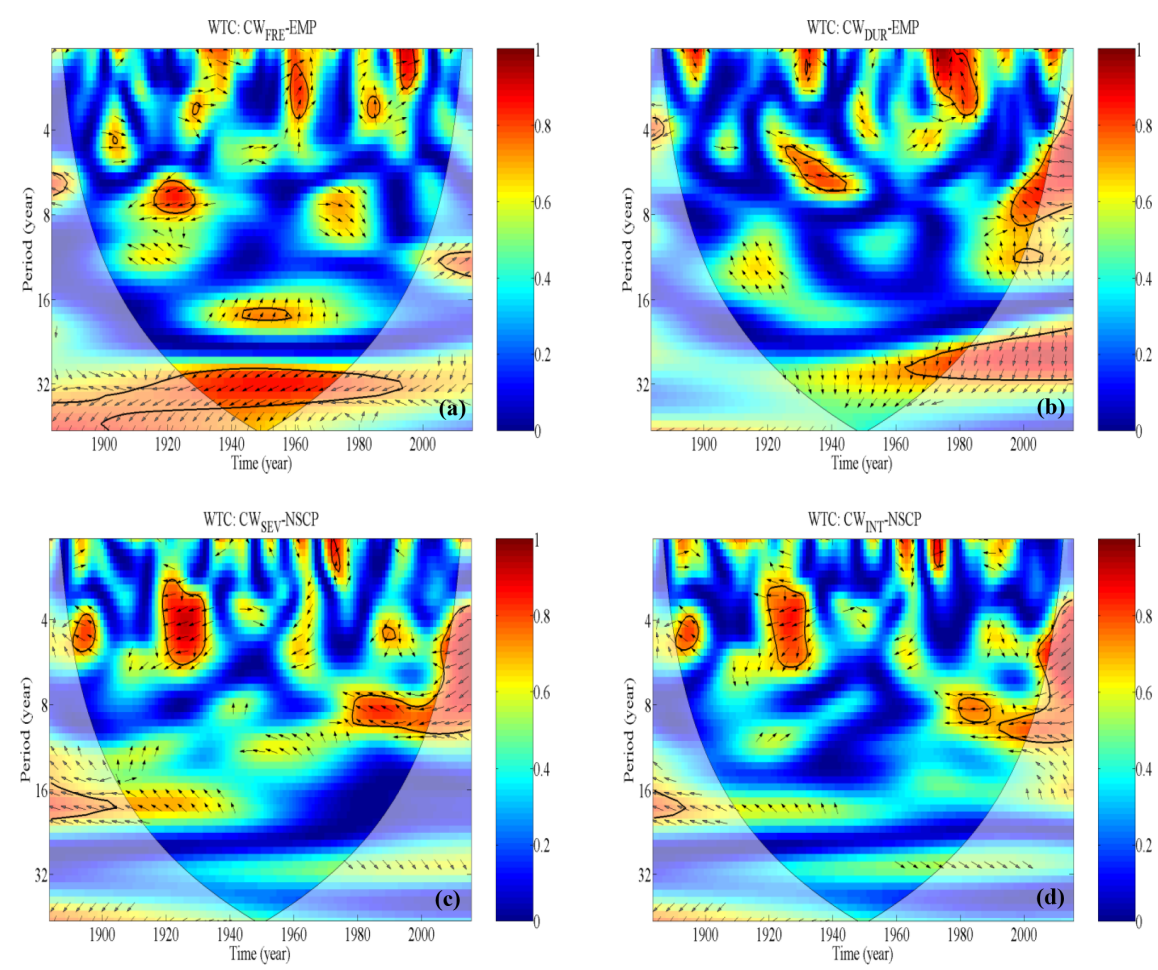

Figure 10. In the left panels, the Wavelet Coherence (WTC) spectra between $\mathrm{CW}_{\mathrm{FRE}}$ and EMP index (a) and between CW $\mathrm{SEV}_{\text {and NSCP }}$ index (c) are presented. In the right panels, the WTC analysis between CW DUR and EMP index (b) and between CW INT and NSCP index (d) are sketched. The black arrows indicate the phase relationship between the respective time series. The thick contour designates the $5 \%$ significance level against red noise; the cone of influence, where edge effects might distort the picture, is shown as a lighter shade. All WTC spectra refer to the period 1884-2015.

(a)

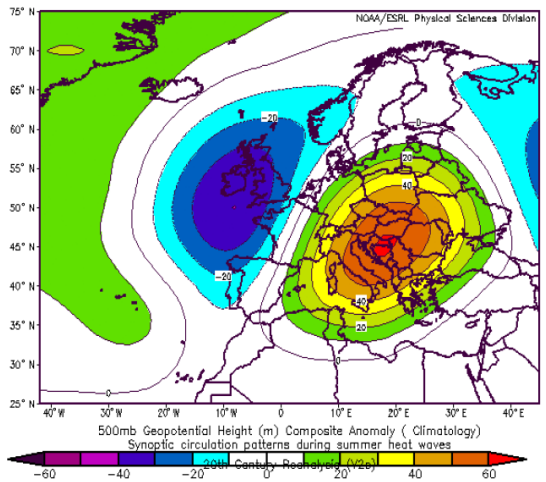

(b)

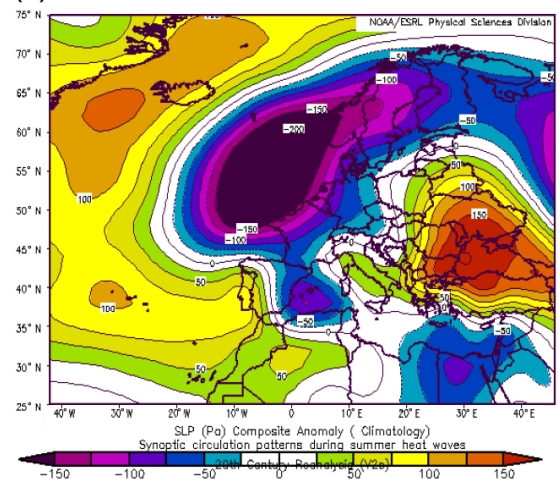

(c)

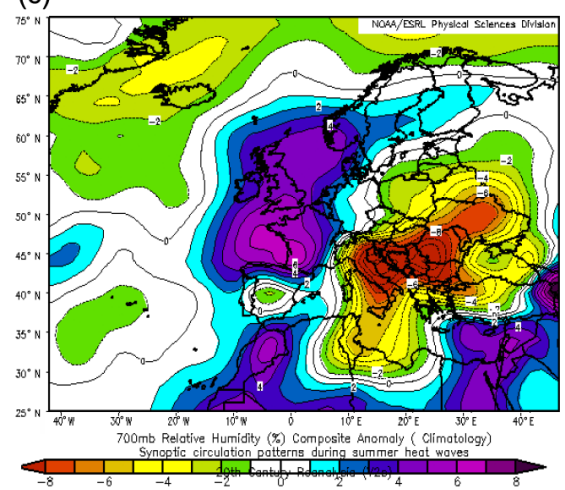

Figure 11. Daily composite of large-scale circulation patterns during summer heat waves (SHW) occurred in Montevergine site (1884-2015 period). Anomalies with respect to 1981-2010 average of three different meteorological fields are shown: (a) presents the anomalies in terms of daily $500 \mathrm{hPa}$ geopotential height (m), (b) in terms of Sea Level Pressure (Pa) and (c) in terms of $700 \mathrm{hPa}$ relative humidity (\%).

2015. In the same manner, the winter CW (hereafter, WCW) include the CW events happened from January to March.

To characterize the synoptic features related to SHW and WCW events occurred in Montevergine site, the daily composites of three meteorological fields have been considered: Z500, SLP and the $700 \mathrm{hPa}$ relative humidity (RH700). The daily composites have been generated through the
NCEP/NCAR 20th Century Reanalysis dataset (Compo et al., 2011). All the meteorological fields have been considered in terms of anomalies against the 1981-2010 average.

Figure 11 shows the composite anomaly of large-scale atmospheric patterns during SHW events. The synoptic circulation is characterized by two main anomalies patterns: one is located in northwestern Europe, the other one extends from 
(a)

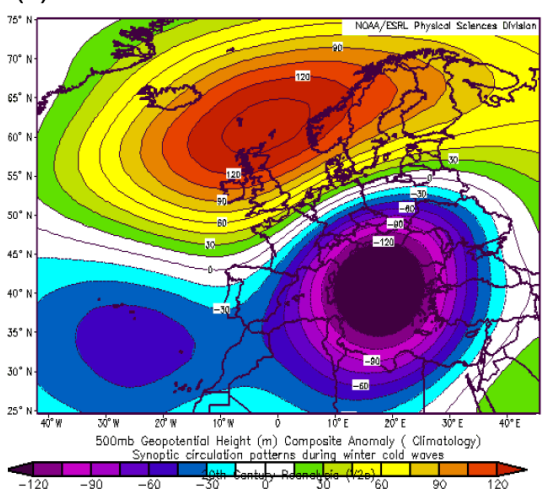

(b)

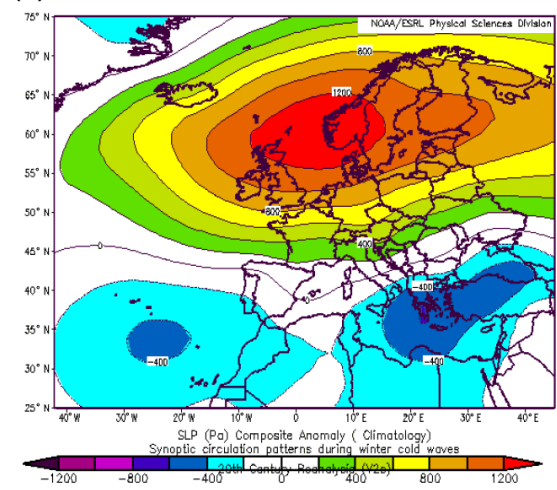

(c)

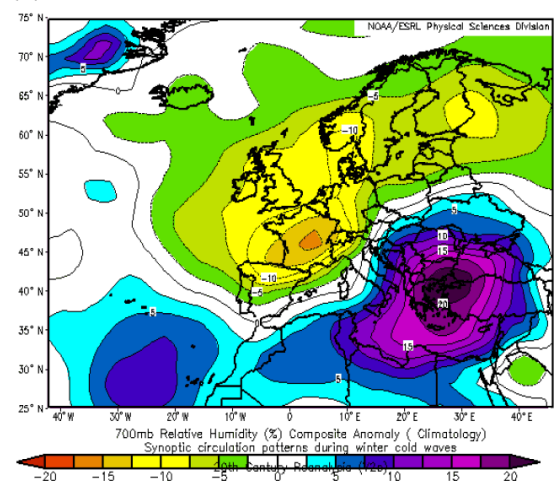

Figure 12. Daily composite of large-scale circulation patterns during winter cold waves (WCW) occurred in Montevergine site (1884-2015 period). Anomalies with respect to 1981-2010 average of three different meteorological fields are shown: (a) presents the anomalies in terms of daily $500 \mathrm{hPa}$ geopotential height (m), (b) in terms of Sea Level Pressure (Pa) and (c) in terms of $700 \mathrm{hPa}$ relative humidity (\%).

Central Mediterranean basin to Eastern Europe. The first pattern is associated with negative anomalies of Z500 and SLP and with a positive anomaly in terms of RH700. The second pattern presents a positive anomaly of Z500 and SLP and a negative anomaly of RH700. This large-scale circulation is very favorable to the advection of warm subtropical air masses over Italian peninsula, especially in central and southern regions. The meridional warm advection is also enhanced by a negative SLP anomaly located in the western Mediterranean basins.

The results obtained for WCW events (Fig. 12) have revealed, in terms of Z500, a positive anomaly over northeastern Atlantic and a deep negative anomaly over central and eastern Mediterranean regions: the upper-level synoptic pattern just described can be related to the positive phase of the EMP teleconnection index. The SLP field exhibits a positive anomaly in the northern Europe and a negative anomaly in eastern Mediterranean basins. Regarding the RH700 field, a prominent positive anomaly has been detected over the southeastern Europe.

\section{Conclusions}

The main aim of this study is to analyze the yearly variability of extreme temperature events, i.e. the heat and cold waves, occurred in the last 130 years in Montevergine, a mountainous site located in the Southern Italy. The analysis has been carried out through the homogenized minimum and maximum temperature time series collected in Montevergine observatory from 1884 to 2015 . In order to account for heat and cold waves (HW and CW, respectively), we have used a combination of percentile-based and duration-based indicators. The results have highlighted an increasing and significant tendency in HW frequency $(+1.16$ events per decade), severity $(+1.15$ severity score per decade) and intensity $(+0.33$ intensity score per decade) in the last four decades (1974-
2015). The CW events have exhibited a significant trend only in terms of intensity in 1914-1943 $(+0.28$ intensity score per decade) and in 1974-2015 (+0.33 intensity score per decade) periods. To investigate about the behavior of the time series in time-frequency domain, we have adopted the Continuous Wavelet Transform (CWT). The latter has allowed detecting the localized intermittent oscillations of the nonstationary analyzed signals. Regarding the HW events, the CWT analysis has highlighted significant fluctuations only in the last three decades. The other three HW signals (duration, severity and intensity) have exhibited relevant oscillations between 1900 and 1980, mainly in the 1-4-year band. The CW time series have shown high power between 1900 and 1920, around 1950 and around 2000, mainly in the 1-8-year band.

In order to identify the physical mechanisms responsible for the variability and the oscillations in time-frequency space highlighted by CWT analysis, we have investigated about the relationships between extreme temperature events occurred in Montevergine and the large-scale atmospheric patterns. This analysis has been performed through the Cross Wavelet Transform (XWT) and the Wavelet Coherence (WTC) tools. The first one allows detecting the areas, in the time-frequency domain, where the CWTs of two determined signals have common power and relative phase, whereas the WTC analysis can be considered as a localized correlation coefficient in time-frequency space between the two time series.

The HW time series have shown relevant linkages with the large-scale atmospheric patterns synthetized by the Western European Zonal Circulation (WEZC) and the North Atlantic Oscillation (NAO) indexes. The WEZC patterns have forced a large part of the high-frequency variability of HW events. According to XWT analysis, in fact, HW time series and WEZC spectra have common areas of high power in the 1-8-year band: in these areas, a direct in-phase relationship among the analyzed signals has been detected. The XWT between HW events and NAO index has highlighted an area 
of high common power in the 8-16-year band. However, in this case, a weak direct phase relationship has been detected among the investigated signals: the cycles of HW time series, in fact, lead those of NAO index by a phase angle of about $45^{\circ}$, which indicates a leading time of about 2 years. The WTC analysis has revealed a relevant coupling between NAO and HW time series from 1920 and 1990 in the 12-16year band. However, the HW cycles lead the ones of NAO index by a phase angle ranging between 45 and $90^{\circ}$ (which corresponds to a lead time of about 3.5 years).

The atmospheric circulation patterns described by the Eastern Mediterranean Pattern (EMP) and by the North Sea Caspian Pattern (NSCP) have regulated the variability of CW events. The first teleconnection index has exhibited connections with $\mathrm{CW}$ frequency and duration time series, whereas the second one has forced the oscillations of CW severity and intensity signals. The WT analysis has shown a relevant coupling between CW frequency time series and EMP on a period of about 32 years: however, the two signals are in a weak anti-phase relationship. Moreover, a significant coherence has been detected between NSCP and CW severity and intensity time series between 1920 and 1940 (in the 3-6-year band) and from 1980 to 2000 (in the 4-9-year band): in both cases, a strong anti-phase relationship between the analyzed signals has been discovered.

The last part of this research has been devoted to the characterization of the large-scale synoptic features which forced the summer heat wave (SHW) and the winter cold wave (WCW) events in Montevergine site. To pursue this aim, three meteorological fields have been considered (in terms of anomalies with respect to the 1981-2010 average): the $500 \mathrm{hPa}$ geopotential height (Z500), the sea level pressure (SLP) and the $700 \mathrm{hPa}$ relative humidity (RH700). Once selected the SHW and WCW events for the period 1884-2015, daily composites have been generated by using the reanalysis provided by NCEP-NCAR. The synoptic pattern associated to SHW events is characterized by negative anomalies of Z500 and SLP in the northwestern Europe and by a prominent positive anomaly in terms of Z500 and RH700 in central Mediterranean regions and eastern Europe. A prominent and strong ridge over the northeastern Atlantic and a deep trough in central and eastern Mediterranean basins characterize the large-scale circulation related to WCW events. This synoptic scenario is very similar to one associated with the positive phase of EMP teleconnection index.

Future studies will be primarily devoted to a further investigation of the physical mechanisms that, according to the results achieved in this study, regulate the variability of HW and $\mathrm{CW}$ events. In this respect, we will explore the usefulness of the empirical orthogonal function, an analysis tool widely used in climate research to study the change in time of the large-scale atmospheric patterns. Furthermore, we will perform also an analysis of seasonal variability and trends of HW and CW events, focusing the attention about winter CW and summer HW events.
Moreover, we are planning to extend the analysis to other climatological time series collected in high-elevation sites in central Mediterranean regions and to investigate about the possible relationships between heat waves and droughts events.

Data availability. The meteorological data collected in Montevergine Observatory are owned by the Benedectine Community of Montevergine Abbey and, therefore, are not publicly accessible. The use of maximum and minimum temperature observations recorded from 1884 to 2015 has been kindly granted to the authors by the Benedectine Community of Montevergine after a request submitted by the Department of Science and Technology of the University of Naples "Parthenope".

Competing interests. The authors declare that they have no conflict of interest.

Acknowledgements. The authors of this work thank the Climate Research Unit of the University of East Anglia (UK), for providing NAO index data, and NCEP/NCAR for the reanalysis. The authors are also grateful to the Benedectine Community of Montevergine Abbey for affording the opportunity to use the original meteorological data collected in Montevergine Observatory.

Edited by: Roberto Deidda

Reviewed by: two anonymous referees

\section{References}

Abeli, T., Rossi, G., Gentili, R., Gandini, M., Mondoni, A., and Cristofanelli, P.: Effect of the extreme summer heat waves on isolated populations of two orophitic plants in the north Apennines (Italy), Nord. J. Bot., 30, 109-115, doi:10.1111/j.17561051.2011.01303.x, 2012.

Alexander, L. V., Zhang, X., Peterson, T. C., Caesar, J., Gleason, B., Klein Tank, A. M. G., Haylock, M., Collins, D., Trewin, B., Rahimzadeh, F., Tagipour, A., Rupa Kumar, K., Revadekar, J., Griffiths, G., Vincent, L., Stephenson, D. B., Burn, J., Aguilar, E., Brunet, M., Taylor, M., New, M., Zhai, P., Rusticucci, M., and Vazquez-Aguirre, J. L.: Global observed changes in daily climate extremes of temperature and precipitation, J. Geophys. Res., 111, D05109, doi:10.1029/2005JD006290, 2006.

Andrade, C., Leite, S. M., and Santos, J. A.: Temperature extremes in Europe: overview of their driving atmospheric patterns, Nat. Hazards Earth Syst. Sci., 12, 1671-1691, doi:10.5194/nhess-121671-2012, 2012.

Baldi, M., Dalu, G., Maracchi, G., Pasqui, M., and Cesarone, F.: Heat waves in the Mediterranean: a local feature or a large-scale effect?, Int. J. Climatol., 46, 1477-1487, 2006.

Beniston, M.: The 2003 heat wave in Europe: A shape of things to come? An analysis based on Swiss climatological data and model simulations, Geophys. Res. Lett., 31, L02202, doi:10.1029/2003GL018857, 2004. 
Brohan, P., Kennedy, J. J., Harris, I., Tett, S. F. B., and Jones P. D.: Uncertainty estimates in regional and global observed temperature changes: a new dataset from 1850, J. Geophys. Res., 111, D12106, doi:10.1029/2005JD006548, 2006.

Brunetti, M., Colacino, M., Maugeri, M., and Nanni, T.: Trends in the daily intensity of precipitation in Italy from 1951 to 1996, Int. J. Climatol., 21, 299-316, 2001.

Brunetti, M. and Kutiel, H.: The relevance of the North-Sea Caspian Pattern (NCP) in explaining temperature variability in Europe and the Mediterranean, Nat. Hazards Earth Syst. Sci., 11, 28812888, doi:10.5194/nhess-11-2881-2011, 2011.

Budillon, G. and Capozzi, V.: Risultati preliminari dell'analisi di una nuova serie di dati climatici nell'Italia meridionale (Osservatorio di Montevergine - AV), Clima del Bacino del Mediterraneo negli ultimi 12 mila anni, Roma, 17 Ottobre 2011, Scienze e Lettere Editore Commerciale, Roma, 189-197, 2012.

Capozzi, V. and Budillon, G.: Time series analyses of climatological records from a high altitude observatory in southern Italy (Montevergine, AV), Proceedings of First Annual Conference "Climate change and its implications on ecosystem and society", Società Italiana per le Scienze del Clima, Lecce, Italy, 2013.

Carril, A. F., Gualdi, S., Cherchi, A., and Navarra, A.: Heatwaves in Europe: Areas of homogenous variability and links with the regional to large-scale atmospheric and SSTs anomalies, Clim. Dynam., 30, 77-98, 2008.

Cassou, C., Terray, L., and Phillips, A. S.: Tropical Atlantic Influence on European Heat Waves, J. Climate, 18, 2805-2811, 2005.

Compo, G. P., Whitaker, J. S., Sardeshmukh, P. D., Matsui, N., Allan, R. J., Yin, X., Gleason, B. E., Vose, R. S., Rutledge, G., Bessemoulin, P., Brönnimann, S., Brunet, M., Crouthamel, R. I., Grant, A. N., Groisman, P. Y., Jones, P. D., Kruk, M., Kruger, A. C., Marshall, G. J., Maugeri, M., Mok, H. Y., Nordli, Ø., Ross, T. F., Trigo, R. M., Wang, X. L., Woodruff, S. D., and Worley, S. J.: The Twentieth Century Reanalysis Project, Q. J. Roy. Meteorol. Soc., 137, 1-28, doi:10.1002/qj.776, 2011.

Della-Marta, P. M., Haylock, M. R., Luterbacher, J., and Wanner, H.: Doubled length of western European summer heat waves since 1880, J. Geophys. Res., 112, D15103, doi:10.1029/2007JD008510, 2007.

Díaz, J., García-Herrera, R., Trigo, R. M., Linares, C., Valente, M. A., De Miguel, J. M., and Hernández, E.: The impact of the summer 2003 heat wave in Iberia: how should we measure it?, Int. J. Biometeorol., 50, 159-166, 2006.

Diodato, N.: Nota climatica ispirata dalla serie storica delle precipitazioni osservate al Santuario di Montevergine, Riv. Meteorol. Aeronau., LII, 179-182, 1992.

Glowienka-Hense, R.: The North Atlantic Oscillation in the Atlantic-European SLP, Tellus A, 42, 497-507, 1990.

Griffiths, G. M., Salinger, M. J., and Leleu, I.: Trends in extreme daily rainfall across the South Pacific and relationship to the South Pacific Convergence Zone, Int. J. Climatol., 23, 847-869, 2003.

Grinsted, A., Moore, J. C., and Jevrejeva, S.: Application of the cross wavelet transform and wavelet coherence to geophysical time series, Nonlin. Processes Geophys., 11, 561-566, doi:10.5194/npg-11-561-2004, 2004.

Hansen, J., Sato, M., Ruedy, R., Lo, K., Lea, D. W., and MedinaElizade, M.: Global temperature change, P. Natl. Acad. Sci. USA, 103, 14288-14293, 2006.
Hatzaki, M., Flocas, H. A., Asinakopoulos, D. N., and Maheras, P.: The eastern Mediterranean teleconnection pattern: identification and definition, Int. J. Climatol., 27, 727-737, 2007.

Hatzaki, M., Flocas, H. A., Giannakopoulos, C., and Maheras, P.: The Impact of the Eastern Mediterranean Teleconnection Pattern on the Mediterranean Climate, J. Climate, 22, 977-992, 2009.

IPCC: Managing the Risks of Extreme Events and Disasters to Advance Climate Change Adaptation. A Special Report of Working Groups I and II of the Intergovernmental Panel on Climate Change, editted by: Field, C. B., Barros, V., Stocker, T. F., Qin, D., Dokken, D. J., Ebi, K. L., Mastrandrea, M. D., Mach, K. J., Plattner, G.-K., Allen, S. K., Tignor, M., and Midgley, P. M., Cambridge University Press, Cambridge, UK, and New York, NY, USA, 582 pp., 2012.

IPCC: Climate Change 2014: Impacts, Adaptation, and Vulnerability. Summaries, Frequently Asked Questions, and Cross-Chapter Boxes. A Contribution of Working Group II to the Fifth Assessment Report of the Intergovernmental Panel on Climate Change, edited by: Field, C. B., Barros, V. R., Dokken, D. J., Mach, K. J., Mastrandrea, M. D., Bilir, T. E., Chatterjee, M., Ebi, K. L., Estrada, Y. O., Genova, R. C., Girma, B., Kissel, E. S., Levy, A. N., MacCracken, S., Mastrandrea, P. R., and White, L. L., World Meteorological Organization, Geneva, Switzerland, 190 pp., 2014.

Kalnay, E., Kanamitsu, M., Kistler, R., Collins, W., Deaven, D., Gandin, L., Iredell, M., Saha, S., White, G., Woollen, J., Zhu, Y., Leetmaa, A., Reynolds, B., Chelliah, M., Ebisuzaki, W., Higgins, W., Janowiak, J., Mo, K. C., Ropelewski, C., Wang, J., Jenne, R., and Joseph, D.: The NCEP/NCAR 40-year reanalysis project, B. Am. Meteorol. Soc., 77, 437-470, 1996.

Kendall, M. G.: Rank Correlation Methods, 3rd Edn., Hafner Publishing Company, New York, 1962.

Klein Tank, A. M. G., Zwiers, F. W., and Zhang, Z.: Guidelines on analysis of extremes in a changing climate in support of informed decisions for adaptation, Climate Data and Monitoring, WCDMP-No. 72, WMO-TD No. 1500, World Meteorological Organization Publication Board, Geneva, Switzerland, 56 pp., 2009.

Kutiel, H. and Benaroch, Y.: North Sea-Caspian Pattern (NCP) an upper level atmospheric teleconnection affecting the Eastern Mediterranean: Identification and definition, Theor. Appl. Climatol., 71, 17-28, 2002.

Mann, H. B.: Nonparametric tests against trend, Econometrica, 13, 245-259, 1945.

Percival, D. B.: Wavelets, in: Encyclopedia of Environmetrics, edited by: El-Shaarawi, A. H. and Piegorsch, W. W., John Wiley \& Sons, Chichester, 4, 2338-2351, 2002.

Peterson, T. C. and Easterling, D. R.: Creation of homogeneous composite climatological reference series, Int. J. Climatol., 14, 671-679, 1994.

Poumadère, M., Mays, C., Le Mer, S., and Blong, R.: The 2003 heat wave in France: dangerous climate change here and now, Risk Anal., 25, 1483-1494, doi:10.1111/j.1539-6924.2005.00694.x, 2005.

Santos, J. and Corte-Real, J.: Temperature Extremes in Europe and Large-Scale Circulation: HadCM3 future scenarios, Clim. Res., 31, 3-18, 2006. 
Santos, J., Corte-Real, J., and Leite, S.: Atmospheric large-scale dynamics during the 2004-2005 winter drought in Portugal, Int. J. Climatol., 27, 571-586, 2007.

Scaife, A. A., Folland, C. K., Alexander, L. V., Moberg, A., and Knight, J. R.: European climate extremes and the North Atlantic Oscillation, J. Climate, 21, 72-83, 2008.

Sillmann, J., Kharin, V. V., Zhang, X., Zwiers, F. W., and Bronaugh, D.: Climate extremes indices in the CMIP5 multimodel ensemble: Part 1. Model evaluation in the present climate, J. Geophys. Res., 118, 1716-1733, 2013.

Slonosky, V. C., Jones, P. D., and Davies, T. D.: Atmospheric circulation and surface temperature in Europe from the 18th century to 1995, Int. J. Climatol., 21, 63-75, 2001.

Smith, T. T., Zaitchik, B. F., and Gohlke, J. M.: Heat waves in the United States: definitions, patterns and trends, Climatic Change, $118,811-825,2013$.
Spinoni, J., Lakatos, M., Szentimrey, T., Bihari, Z., Szalai, S., Vogta, J., and Antofiea, T.: Heat and cold waves trends in the Carpathian Region from 1961 to 2010, Int. J. Climatol., 35, 4197-4209, 2015.

Torrence, C. and Webster, P.: Interdecadal Changes in the ESNOMonsoon System, J. Climate, 12, 2679-2690, 1999.

Wallace, J. and Gutzler, D.: Teleconnections in the geopotential height field during the Northern Hemisphere winter, Mon. Weather Rev., 109, 784-812, 1981.

Xoplaki, E., Gonzalez-Rouco, J., Luterbacher, J., and Wanner, H.: Mediterranean summer air temperature variability and its connection to the large-scale atmospheric circulation and SSTs, Clim. Dynam., 20, 723-739, 2003.

Zhang, X., Alexander, L., Hegerl, G. C., Jones, P., KleinTank, A. M. G., Peterson, T. C., Trewin, B., and Zwiers, F. W.: Indices for monitoring changes in extremes based on daily temperature and precipitation data, WIREs Clim. Change, 2, 851-870, 2011. 